\title{
Control of Renal Factors in Plasma Homovanillic Acid Measurements
}

\author{
Farooq Amin, M.D., Adriana E. Stroe, M.D., Thomas Kahn, M.D., Peter J. Knott, Ph.D.,
} Rene S. Kahn, M.D., and Michael Davidson, M.D.

To identify and control renal factors affecting plasma homovanillic acid (HVA), a dopamine metabolite and an indicator of brain dopamine activity in clinical research, nine healthy subjects were studied on 5 nonconsecutive days. First study day was the baseline and on the other days base, salt, water, or probenecid loads were given. On each day serial concentrations of HVA and serotonin metabolite 5-hyroxyindoleacetic acid (HIAA), another organic anion, in plasma were measured. Results suggested that base, salt, and water loads did not affect plasma concentrations of either metabolite. Probenecid, which partially blocks renal organic anion transport, induced similar increases in plasma HVA and HIAA. When plasma HVA:HIAA ratio was used to control for the effect of probenecid, differences between baseline and probenecid days were no longer significant. Results suggest that HVA and HIAA are similarly handled by the kidney and that simultaneously measured plasma HIAA could be used to distinguish renal influences in plasma HVA studies.

[Neuropsychopharmacology 18:317-320, 1998]

(C) 1998 American College of Neuropsychopharmacology

Published by Elsevier Science Inc.
KEY WORDS: Homovanillic acid; 5-Hydroxyindoleacetic acid; Dopamine; Serotonin; Plasma; Renal factors

Plasma concentrations of the major dopamine (DA) metabolite homovanillic acid (HVA) are useful indicators of brain DA activity in clinical research (Amin et al. 1992; Amin and Friedhoff 1997). It is the most suitable instrument currently available to assess DA activity under relatively natural behavioral conditions, i.e., without any pharmacological manipulations or inducing stress from study conditions. However, plasma HVA (pHVA) concentrations are not only determined by its production rates but also by its renal excretion rates. Satisfac-

From the Houston VAMC and Baylor College of Medicine (FA, AES), Houston, Texas; the Bronx VAMC and Mount Sinai School of Medicine (TK, PJK), New York; Department of Psychiatry (RSK), University Hospital Utrecht, The Netherlands; and the Sheba Medical Center (MD), Tel Hashomer, Israel.

Address correspondence to: Farooq Amin, M.D., Psychiatry Service (116A), Houston VA Medical Center, 2002 Holcombe, Houston, TX 77030.

Received April 25, 1997; accepted July 24, 1997. tory methods are not currently available to account for the variance due to renal excretion in pHVA studies. Measurement of urinary HVA is often not feasible and has other limitations (Amin et al. 1992). The usefulness of renal plasma clearance (Potter et al. 1989) (RPC) is limited because it depends on urinary HVA measurement. Furthermore, RPC is calculated by dividing the amount of excreted HVA with its plasma concentration. If plasma concentration changes due to a variation in its production, the calculated RPC would also reflect a change despite unchanged excretion. Therefore, the usefulness of RPC is limited when production rates are not constant, such as during morning hours (Stroe et al. 1997) when pHVA is often measured in clinical studies.

The study presented here is an attempt to identify and control some of the variables that can affect renal HVA excretion and hence pHVA concentrations. HVA is mainly excreted by the kidney via an organic anion transport system, which is a nonspecific mechanism shared by many other anions including the serotonin metabolite 5-hydroxyindoleacetic acid (HIAA) (Amin et al. 1992). The excretion of some organic anions can also 
Table 1. Plasma HVA and HIAA on 4 Study Days

\begin{tabular}{|c|c|c|c|c|c|c|}
\hline \multicolumn{2}{|c|}{ Study Day } & \multicolumn{4}{|c|}{ Plasma HVA and HIAA, Mean \pm SEM (nM/L) } & \multirow{2}{*}{$\begin{array}{c}\text { Comparison with } \\
\text { Baseline Day } \\
\begin{array}{c}\text { Repeated Measure Anova, } \\
\text { Day by Time Interactions }\end{array}\end{array}$} \\
\hline & & 9:00 A.M. & 11:00 A.M. & 12:30 P.M. & 2:00 P.M. & \\
\hline Day 1 & HVA & $58.9 \pm 7.0$ & $47.4 \pm 3.7$ & $43.5 \pm 3.0$ & $42.8 \pm 2.3$ & - \\
\hline (Baseline) & 5-HIAA & $42.8 \pm 5.0$ & $43.0 \pm 3.0$ & $39.4 \pm 3.4$ & $39.0 \pm 4.2$ & - \\
\hline Day $2^{a}$ & HVA & $68.8 \pm 11.7$ & $50.0 \pm 6.7$ & $43.1 \pm 4.2$ & $43.5 \pm 5.6$ & $\mathrm{~F}=3.74 p<0.02^{b}$ \\
\hline (Base load) & 5-HIAA & $44.5 \pm 7.0$ & $41.2 \pm 6.9$ & $38.2 \pm 5.0$ & $36.0 \pm 4.9$ & $\mathrm{~F}=0.36 p=\mathrm{NS}$ \\
\hline Day $3^{c}$ & HVA & $59.4 \pm 8.3$ & $48.3 \pm 4.6$ & $43.5 \pm 4.0$ & $41.8 \pm 3.7$ & $\mathrm{~F}=0.35 p=\mathrm{NS}$ \\
\hline (Salt load) & 5-HIAA & $48.0 \pm 4.4$ & $41.5 \pm 4.6$ & $43.4 \pm 8.2$ & $37.2 \pm 4.9$ & $\mathrm{~F}=0.74 p=\mathrm{NS}$ \\
\hline Day $4^{d}$ & HVA & $56.7 \pm 6.7$ & $45.4 \pm 3.6$ & $42.4 \pm 3.0$ & $41.2 \pm 3.1$ & $\mathrm{~F}=0.17 p=\mathrm{NS}$ \\
\hline (Water load) & 5-HIAA & $45.7 \pm 4.3$ & $37.6 \pm 3.5$ & $38.4 \pm 4.5$ & $38.9 \pm 4.9$ & $\mathrm{~F}=1.21 p=\mathrm{NS}$ \\
\hline
\end{tabular}

${ }^{a}$ Base load changed urine $\mathrm{pH}$ from 6.48 on day 1 at 2:00 P.M. to 7.95 on day 2 (paired $t=9.0, p<.0005$ ).

${ }^{b}$ This apparently significant result was due to an outlier at 9:00 A.M. (before base load was given). Results were not significant otherwise.

${ }^{c}$ Salt load changed urine sodium concentration from $68.5 \mathrm{mEq} / \mathrm{L}$ on day 1 at 2:00 P.M. to $208.1 \mathrm{mEq} / \mathrm{L}$ on day 3 (paired $t=11.0, p<.0005$ ).

${ }^{d}$ Water load changed urine flow rate from $1.96 \mathrm{ml} / \mathrm{min}$ on day 1 to $4.5 \mathrm{ml} / \mathrm{min}$ on day 4 (paired $t=5.3, p<.001$ ).

be influenced by changes in urine $\mathrm{pH}$ and urine output as discussed elsewhere (Amin et al. 1992). In this study, the effect of partially blocking the renal organic anion excretion by probenecid on pHVA was examined. Effects of changes in urine $\mathrm{pH}$ and in salt or water intake on pHVA were also investigated. Plasma concentrations of HIAA (pHIAA), derived mostly from peripheral serotonin metabolism, were also studied for possible similarities to pHVA in response to manipulations that can affect renal excretion of some organic anions. Renal organic anion mechanism was first described in relation to HIAA (Despopoulos and Weissbach 1957), and its re-

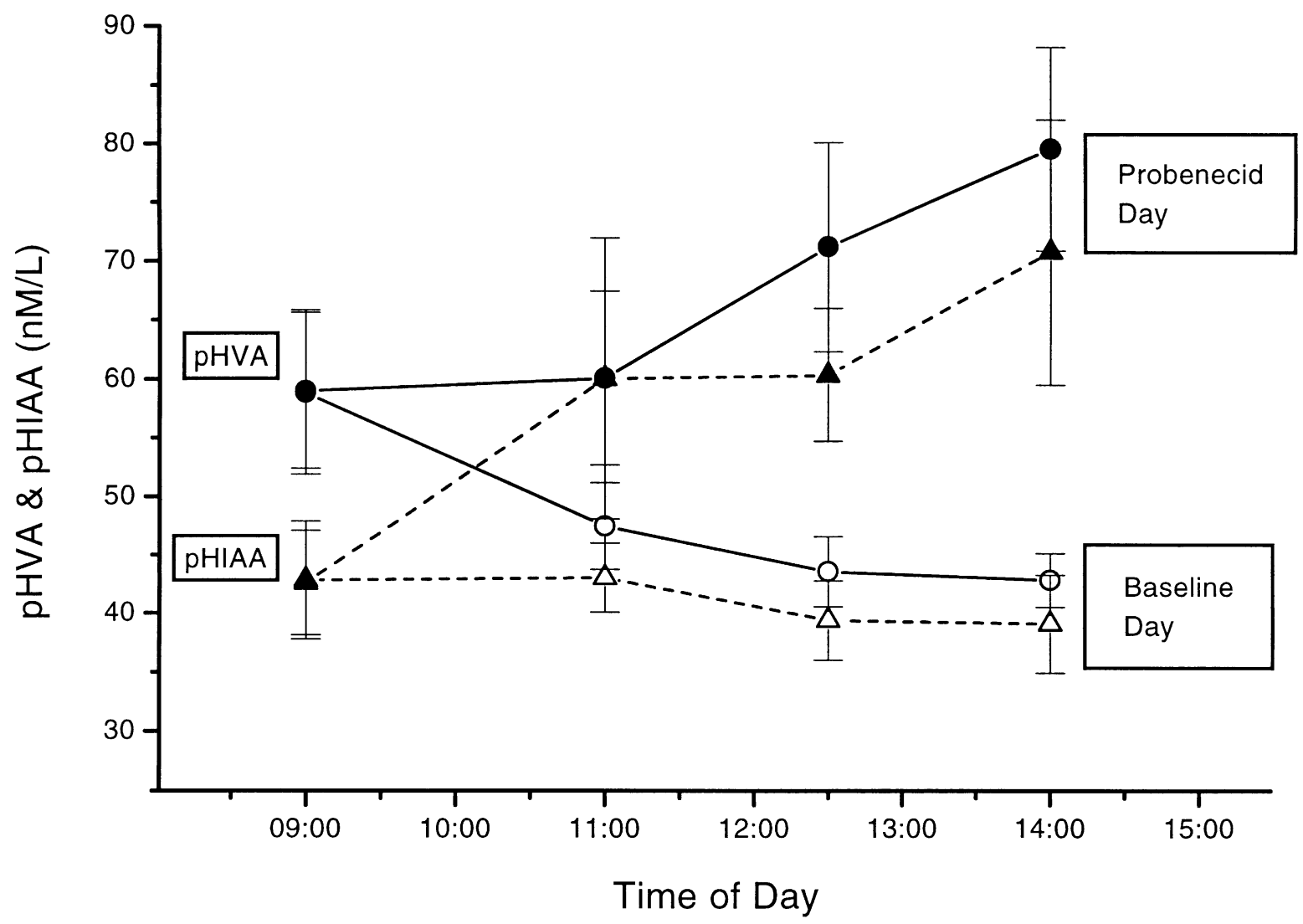

Figure 1. Plasma HVA (circles, solid lines) and plasma HIAA (triangles, dashed lines) on baseline day (open circles and triangles) and probenecid day (solid circles and triangles). Error bars reflect standard errors of the mean. The effect of probenecid was highly significant both on plasma HVA (repeated measure ANOVA, day by time interaction, $\mathrm{F}=19.5 ; d f=3,24 ; p<.0005$ ) and on plasma HIAA (repeated measure ANOVA, day by time interaction, $\mathrm{F}=14.8 ; d f=3,21 ; p<.0005$ ). 


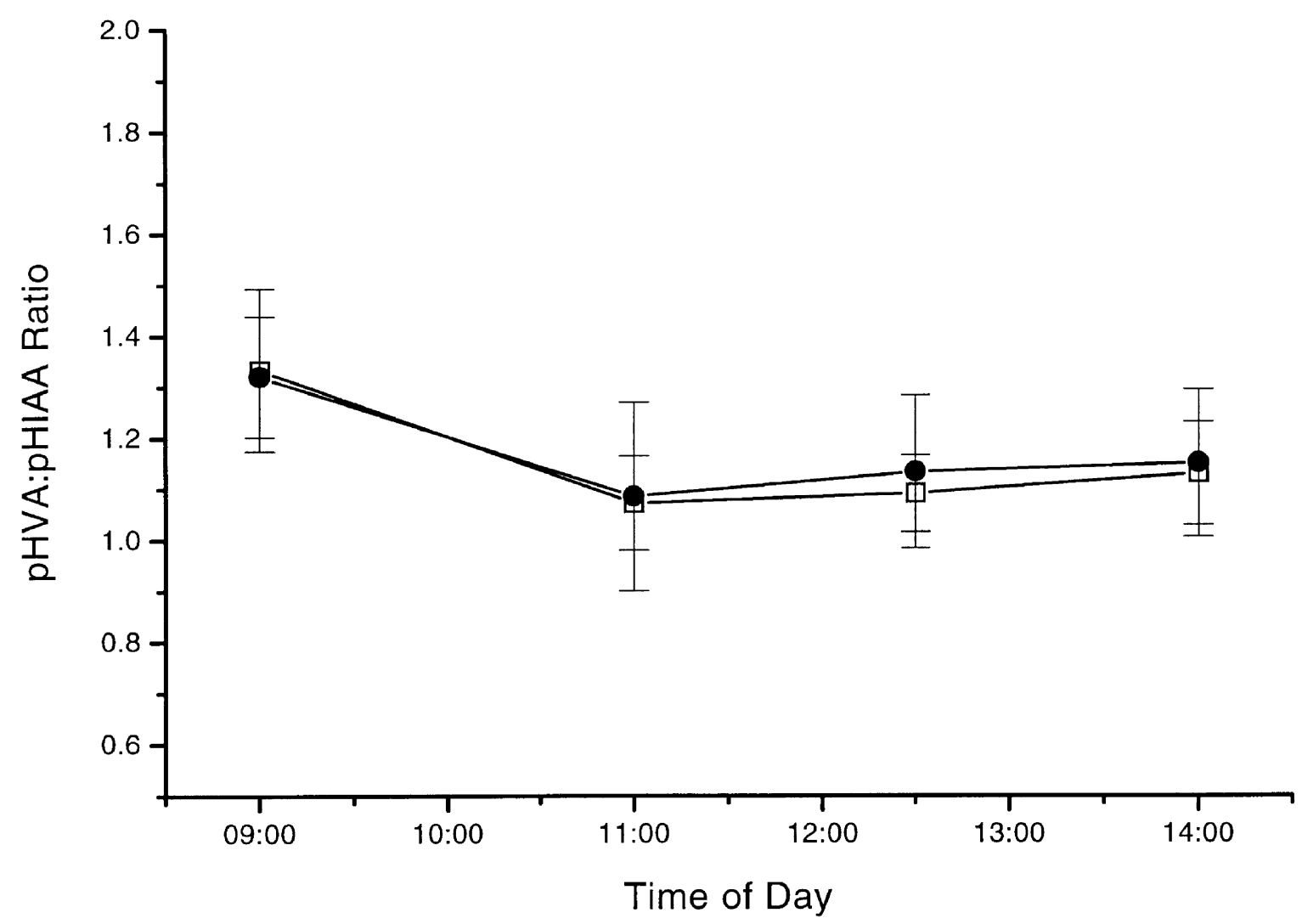

Figure 2. Plasma HVA:HIAA ratio on baseline day (open squares) and on probenecid day (solid circles). Error bars reflect standard errors of the mean. Differences between the two days were not significant (repeated measure ANOVA, day by time interaction, $\mathrm{F}=0.04 ; d f=3,21 ; p=\mathrm{NS}$ ).

nal handling has been well studied (Sulyok et al. 1995; Burtin et al. 1993; Hannedouche et al. 1989).

\section{METHODS}

Nine physically healthy male volunteers who were free of major psychiatric disorders were studied on 5 nonconsecutive days. For each study day, subjects observed a low monoamine diet for $72 \mathrm{~h}$, fasted overnight, avoided smoking and strenuous activity on study mornings, and arrived at the medical center by 8:15 A.M. An intravenous line was started at 8:45 A.M. and $100 \mathrm{ml} / \mathrm{h}$ of $5 \%$ dextrose solution was infused over $5 \mathrm{~h}$. Blood samples were collected at 9:00 A.M., 11:00 A.M., 12:30 P.M., and 2:00 P.M. Platelet-poor plasma was obtained immediately and stored at $-80^{\circ} \mathrm{C}$ until assayed using high performance liquid chromatography (HPLC) methods as in previous studies for HVA (Amin et al. 1995) and for HIAA (Tagari et al. 1984).

Day 1 was the baseline day. Additional procedures on other days were as follows. On day 2, after collecting the 9:00 A.M. blood sample, a base load of sodium bicarbonate at a rate of $44 \mathrm{mEq} / \mathrm{h}$ was infused for $5 \mathrm{~h}$ to alka- linize urine. On day 3 , a salt load of sodium chloride at a rate of $44 \mathrm{mEq} / \mathrm{h}$ was infused for $5 \mathrm{~h}$. On day 4 , a water load of $5.5 \mathrm{ml} / \mathrm{kg} / \mathrm{h} 5 \%$ dextrose was infused for $5 \mathrm{~h}$. On day 5, $1 \mathrm{~g}$ of probenecid was given orally at 9:00 A.M. and then again at 10:00 A.M. Repeated measure analysis of variance (ANOVA) was used to compare baseline day with other study days to analyze the effect of study manipulation on pHVA and pHIAA. Blood samples were not available for pHIAA in one subject.

\section{RESULTS}

A significant decline in pHVA but not in pHIAA was observed on baseline day consistent with the known diurnal variation in pHVA (Doran et al. 1985; Sack et al. 1988; Stroe et al. 1997). Compared with day 1, no significant differences were observed over time for pHVA or pHIAA on day 2 , day 3 , or day 4 (Table 1 ). On day 5 , highly significant differences over time were observed for pHVA as well as pHIAA compared with day 1 (Figure 1), and probenecid treatment induced similar increases of $86 \%$ and $81 \%$ in these two metabolites, respectively. However, when pHVA:pHIAA ratio was used 
(to investigate the relative effect of probenecid on the two metabolites and as a way to control for the effect of probenecid in this study) the difference between day 5 and day 1 was no longer statistically significant (Figure 2).

\section{CONCLUSIONS}

The results suggest that variations in urinary $\mathrm{pH}$ and salt or water intake do not substantially affect pHVA or pHIAA concentrations and that these factors do not need to be controlled in future pHVA studies. These negative results are unlikely to be due to inadequacy of renal manipulations since changes in urine $\mathrm{pH}$, urine sodium concentrations and urine flow rate were large (Table 1) and were sustained for several hours. Examination of pHVA and pHIAA data at 2:00 P.M. did not suggest even trends of any change on days 2,3, and 4 compared with the baseline day (Table 1).

The effect of partially blocking renal organic anion excretion by probenecid appeared to be very similar on both pHVA and pHIAA concentrations. Similarities of pHVA and pHIAA responses to the studied renal manipulations are consistent with the view that HVA and HIAA are similarly handled by the kidney. These results suggest that under suitable conditions, pHIAA can be used as an indicator of renal organic anion excretion in pHVA studies. Simultaneous measurement of pHIAA along with pHVA is convenient and can help distinguish if a pHVA finding is due to renal HVA excretion. For example, if a pHVA finding is due to renal excretion, the variance contributed by renal organic anion excretion would be shared by both pHVA and pHIAA, and the finding is not likely to remain significant when the variance of pHIAA is statistically controlled. On the other hand, if a pHVA finding is not due to renal HVA excretion (and is due to variance in HVA production), it is likely to remain significant even after statistically controlling for pHIAA.

\section{ACKNOWLEDGMENTS}

This work was based on support provided to Dr. Farooq Amin by the Office of Research \& Development, Medical Research Service of Department of Veterans Affairs.

\section{REFERENCES}

Amin F, Davidson M, Davis KL (1992): Homovanillic acid measurement in clinical research: A review of methodology. Schizophr Bull 18:123-148

Amin F, Davidson M, Kahn RS, Schmeidler J, Stern R, Knott, PJ, Apter S (1995): Assessment of the central dopaminergic index of plasma HVA in schizophrenia. Schizophr Bull 21:53-66

Amin F, Friedhoff AJ (1997): Plasma homovanillic acid as a tool to investigate brain dopaminergic activity. In Friedhoff AJ, Amin F (eds), Plasma Homovanillic Acid in Schizophrenia: Implications for Presynaptic Dopamine Dysfunction. Washington, DC, American Psychiatric Press, pp 1-16

Burtin M, Elghozi JL, Laude D, Kleinknecht C (1993): Species differences in mammalian renal function: 5-HIAA, a reported marker of tubular secretion in humans, is handled exclusively by filtration in the rat. Exp Nephrol 1:62-64

Despopoulos A, Weissbach H (1957): Renal metabolism of 5-hydroxyindoleacetic acid. Am J Physiol 189:548-550

Doran AR, Pickar D. Labarca R, Douillet P, Wolkowitz OM, Thomas JW, Roy A, Paul SM (1985): Evidence for a daily rhythm of plasma HVA in normal controls but not in schizophrenic patients. Psychopharmacol Bull 21:694697

Hannedouche T, Laude D, Dechaux M, Grunfeld JP, Elghozi JL (1989): Plasma 5-hydroxyindoleacetic acid as an endogenous index of renal plasma flow. Kidney Int 35:95-98

Potter WZ, Hsiao JK, Goldman SM (1989): Effects of renal clearance on plasma concentrations of homovanillic acid. Methodologic cautions. Arch Gen Psychiatry 46: 558-562

Sack DA, James SP, Doran AR, Sherer MA, Linnoila M, Wehr TA (1988): The diurnal variation in plasma homovanillic acid level persists but the variation in 3-methoxy-4hydroxyphenylglycol level is abolished under constant conditions. Arch Gen Psychiatry 45:162-166

Stroe AE, Amin F, Hashmi A, Densmore D, Kahn T, Knott PJ (1997): Diurnal variation in plasma homovanillic acidnot a renal phenomenon. Biol Psychiatry 41:621-623

Sulyok E, Nagy L, Baranyai Z, Thonney M, Guignard JP (1995): Comparison of 5-hyroxyindole-acetic acid and para-amino hippurate clearances in newborn rabbits. Clin Chim Acta 240:155-161

Tagari PC, Boullin DJ, Davies CL (1984): Simplified determination of serotonin in plasma by liquid chromatography with electrochemical detection. Clin Chem 30:131-135 